\title{
Action Learning - a Learning and Teaching Method in the Preparation Programme for Supervisors of Midwives
}

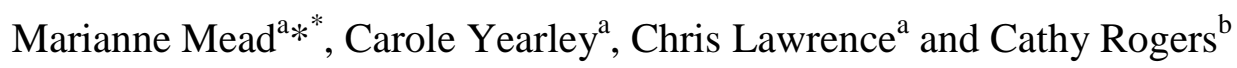

${ }^{a}$ University of Hertfordshire, UK

${ }^{\mathrm{b}}$ Barnet \& Chase Farm NHS Trust, UK

* Corresponding author. School of Nursing and Midwifery, University of Hertfordshire, Hatfield, Herts. AL10 9AB, UK. Email m.m.p.mead@herts.ac.uk 


\title{
Action Learning - a Learning and Teaching Method in the Preparation Programme for Supervisors of Midwives
}

\begin{abstract}
Supervision of midwives is a statutory responsibility which provides a mechanism for support and guidance to every practising midwife in the United Kingdom. To be eligible for appointment as a supervisor, midwives are required to undertake a preparation programme successfully. Because of the changing nature of the professional role and education, the level of the programme of preparation has evolved from an attendance course, to programmes delivered at diploma, degree and, more recently, Masters' level. In collaboration with clinical colleagues and the statutory authorities, the University of Hertfordshire has presented a programme of preparation at Masters' level since 1997. Revalidation in 2001 provided the opportunity to review the learning and teaching methods, and a decision was made to use Action Learning as an important component of the new programme that commenced in 2002. Alongside the normal university quality assessment mechanisms, a systematic evaluation was undertaken to explore the acceptability and perceived usefulness of Action Learning by the students of the second and third cohorts. This paper presents the findings of this evaluation.
\end{abstract}




\section{Keywords}

Supervision of midwives, Action Learning 


\section{Background}

Supervision of midwives (supervisor of midwives) is a statutory responsibility which provides a mechanism for support and guidance to every practising midwife, and more recently also to student midwives, in the United Kingdom. "The role of a supervisor of midwives is to protect the public by empowering midwives and midwifery students to practise safely and effectively. Supervisors are accountable to the local supervising authority for all supervisory activities. When midwives are faced with a situation where they feel they need support and advice the supervisor acts as a resource. Supervisors can also assist in discussions with women when concerns are expressed regarding the provision of care" (NMC, 2004, p26).

The Nursing and Midwifery Council (NMC) applies the legislation relating to the supervision of midwives, according to the Nurses, Midwives and Health Visitors Act 1999. The NMC has the authority to stipulate the eligibility criteria for the appointment of midwives as supervisors of midwives (NMC, 2004). On behalf of the NMC, the local supervisory authority midwifery officers select midwives to undertake a preparation course and appoint successful graduates in each local supervisory authority region in accordance with Rule 11 of the Midwives Rules and Standards (NMC, 2004).

The history of midwifery supervision reveals a shift from a punitive mechanism, which sought to control the practice of midwives from its initial 
inception in 1902, (Donnison, 1988; Heagerty, 1996) to a proactive and enabling model aimed at providing professional support and advice (Stapleton et al., 1998; Duerden, 2005).

The sphere of midwifery practice is identified in the Midwives Rules and Standards (NMC, 2004). The basic standards for midwives include the maintenance and development of her competence, including those necessary for new skills required for her practice (NMC, 2004, p17). The midwife's role is now being extended to include duties previously undertaken by other health professionals, e.g. examination of the newborn (Wolke et al., 2002; Bloomfield et al., 2003; Rogers et al., 2003), antenatal ultrasounds (MagillCuerden, 1994; Fennell, 1995), vacuum extraction (Parslow, 1997; Alexander et al., 2002). It follows that these developments demand that supervision of midwives must adapt if it is to keep pace with professional changes. A sound preparation and education programme is therefore essential if supervisors of midwives are to contribute to the development of excellence in midwifery practice; thereby contributing to ensure public protection.

The guidelines provided by the then English National Board for Nursing, Midwifery and Health Visiting (ENB) stipulated that a curriculum for the preparation of supervisors of midwives must be developed in partnership between a higher education institution and the relevant local supervisory authority midwifery officers $(\mathrm{ENB}, 2001)$ to meet the programme content 
and duration required by Rule 11 of the Midwives Rules and Standards on supervision of midwives (NMC, 2004). Within this framework, various programmes have evolved, from an initial two or three days preparation course to a Masters level programme. The first Masters programme, validated at the University of Hertfordshire in 1997, set a new national standard for the preparation of supervisors of midwives (Rogers \& Hallworth, 2000).

After the delivery of the initial five years of the programme, a periodic review provided an opportunity to re-examine its content, structure and delivery. The initial programme followed a traditional educational approach made up of taught sessions and practice opportunities. Appraisal of the Action Learning (AL) approach led the programme management committee to decide to incorporate its principles and practices into the new programme of preparation validated in 2002. AL is a problem solving approach initially developed for managers in industry. It uses a continuous process of action and reflection, in the context of a supportive group, known as the AL set, to solve a complex problem identified by the learner as needing a solution (McGill \& Beaty, 1995). In this context learning is achieved through a combination of problem identification and questioning, leading to new insight and the reinterpretation of existing knowledge, rather than through the acquisition of fresh knowledge (Revans, 1998). More recently, AL has been seen to have the potential to develop a relevant, transferable and sustained range of cognitive and behavioural outcomes. This is pertinent to 
both individual and organisational requirements, enabling both parties to grow and develop from the dynamics of the learning environment (Marquardt \& Waddill, 2004).

Apart from the reduction in the theory-practice gap (Graham, 1995), AL also aims to encourage learning through increased personal awareness and insight (Weinstein, 1999). Its use in facilitating the development of behaviours, skills and knowledge for practical use has been positively evaluated within other educational initiatives, e.g. the acquisition of transferable skills to support nurses in the transition from general to specialist cancer and palliative care (Rosser et al., 2004), and project management and delivery in the National Health Service (NHS) (Booth et al., 2003). The use of the AL set is a key aspect of AL. Its purpose is to encourage reflection and analysis by the problem holder through constructive questioning. In this way, it becomes a learning tool and a valuable resource for all members of the set.

Students selected to undertake the supervisor of midwives' preparation are all experienced midwives about to undertake a senior leadership role within the profession. They each bring a wealth and range of experiences and knowledge providing a rich source of information (Rogers \& Hallworth, 2000), which AL facilitation can help access, interpret and understand (Pedler, 2005). The supervisor of midwives' role in principle privileges the adult learning approach and enables supervisor of midwives to interact with 
colleagues who bring their own experience to their professional role. Many education theorists support the view that adult learners favour learning methods that integrate past and present personal activities and experiences with new knowledge (Marquardt \& Waddill, 2004). AL enables participants to integrate knowledge with real-life situations because, by its very nature, it embraces, respects and values learning for the individual, the group and the organisational setting (Knowles, 1984; Revans, 1998; Marquardt \& Waddill, 2004). AL offers scope for immediate and future personal learning and development because the skills learned are transferable (Weinstein, 1999) and should therefore enable practitioners to be effective not only as supervisors of midwives, but also in their other professional roles. AL should therefore have the potential to meet the expectations of this preparatory programme for supervisors of midwives.

The University of Hertfordshire (UH) supervisor of midwives' preparation programme is a part-time course of sixteen study days, delivered over 30 weeks. Six of the study days, about one a month, are designated as AL days. Students are expected to attend all these study days. Following the AL principles identified by Weinstein (1999), students are allocated to a learning set and remain with that group for the duration of the programme. Each learning set has a set advisor. Every effort is made to ensure that learning sets are made up of members from differing NHS Trusts and practice areas to ensure diversity of shared experiences, thereby enhancing sharing and learning within the AL set. Setting up appropriately sized 
learning sets, developing reflective learning skills as well as questioning and listening techniques, become fundamental tools for the learners. They enable the group to explore and share ideas, challenge assumptions, and review proposals and strategies for further action and learning (Weinstein, 1999).

During the AL meeting, each member has an allotted time during which they present their actions, problems or issues to the learning set. At this point, this AL set member becomes the "problem holder" and is helped by the other set members to review the problem/situation/opportunity in such a way that new approaches and learning begin to emerge. In turn, each member benefits from the attention of colleagues who develop skills of listening, diagnosis and analysis to help the problem holder understand the situation better and take practical action. The problem holder may use their allotted air space as they wish, however the main thrust of the work of the learning set is aimed at achieving practical solutions to a problem (Weinstein, 1999). In this context, group members often use their time to explore the progress of their personal growth as a supervisor of midwives and the development of their supervisory project.

The processes of delivering and supporting AL sets includes adherence by the set members and advisor to ground rules consisting of a mutually agreed code of conduct. This is intended to ensure that overt, concealed and transferable learning remains central in the AL process (Weinstein, 1999). 
The work of the set must be confidential and this is agreed during the first meeting. The role of the set advisor is to help the learning set work effectively. Their task is to "hold" the members of the group to their agreed task during their air space. The set advisor models a style of questioning, encouraging others to learn and adopt this skill, so they too can explore the problem under examination. In addition, the set advisor draws attention to the processes going on in the set: how and what is being learned, how the set members are behaving and feeling (Weinstein, 1999).

Informal feedback suggested that the experience of AL has been perceived as a significant resource during the programme and continued to offer an informal support network following completion of the course and professional appointment of successful students as supervisors of midwives. Existing internal academic quality monitoring systems provided valuable information that continued to inform the ongoing development of the programme. Modifications following students' feedback have, for example, included more preparatory information on the purpose and practicalities of $\mathrm{AL}$ at the outset of the course. However, specific monitoring and evaluation of the effectiveness of the AL innovation component was necessary to establish if the original aims were being achieved. After running the programme for two years, this evaluation aimed to explore if (1) students perceived that $\mathrm{AL}$, in the context of an education programme for the preparation of supervisors of midwives provided by one institution of higher 
education, equipped them to undertake their professional role, and (2) there was an improvement in students' satisfaction of the AL aspect of the course.

\section{Methods}

Within the context of student evaluation of the programme, a questionnaire based on the principles expressed by Weinstein (1999) was devised to assess and evaluate the impact of the AL approach. After validation in 2002, one cohort of supervisor of midwives students piloted the questionnaire; following initial analysis, it was reviewed and finalised, and subsequently administered to the following two cohorts of students. The results of the last two cohorts are reported here.

Four main areas were evaluated: explanations and principles of AL (Questions 1 to 5), the AL set (Questions 6 to 19), the AL set advisor (Question 20 to 25) and the AL set members (Questions 26 to 34). Students were also asked to comment on their perception of the transferability of the skills they had gained from taking part in AL for other SOM roles (Questions 35 to 38). Six points Likert scales - from 1 = very strongly agree to $6=$ very strongly disagree - were used for each question, so that a lower score would demonstrate a higher level of satisfaction. The data were coded and entered on SPSS for Windows, version 11.0. Frequency distributions and other descriptive statistics were used to describe the findings of the two cohorts; Mann Witney tests were used for the comparison of ordinal variables in the two independent groups. The significance level was set at $p$ 
$<0.05$. Each area of investigation also included a box for comments, should the respondents wish to add any further information. Very few comments were provided and some of these were used to illustrate some of the respondents' reactions.

The same three experienced midwife lecturers, two of whom are Supervisors of midwives, were set advisors of the AL sets for the two cohorts. None had prior AL experience, and all three followed the same preparation for the AL set leader role. All students of two cohorts were informed of the on-going evaluation at the beginning of the course. In the context of normal university practice of quality monitoring and evaluation, the questionnaires - together with normal programme evaluation forms were distributed during the last study day of both courses and students were asked to fill them in and return them to the course leader on the same day. Students were made aware of the voluntary nature of their participation in the completion of the evaluation questionnaire.

\section{Findings}

Sixteen supervisor of midwives students took part in the first cohort and fifteen returned their completed questionnaire. All twelve students of the second cohort returned their questionnaire. Only one respondent from the second cohort had previous experience of AL. 
Five questions on the explanation given on the principles of AL dealt with the individual's responsibility, the purpose of AL, the role of the set advisor, the project students has to complete and the working of the AL set. The scores generally revealed a high level of satisfaction, with scores varying between 1.8 and $2.2(1=$ very strongly agree and $6=$ "very strongly disagree") on these five parameters, but with no significant difference between the two cohorts on these five questions. However, in the first cohort, five "disagree" scores (Likert scale scores 4-6) were registered for these five questions compared to only one for the 2005 cohort; this suggests that the increased preparation of the students for their AL experience might have resulted in an increased perception of preparation for AL in the second cohort. Students were able to add comments to each section of the questionnaire, but very few were filled in, and for this section, two comments identified clear differences of perception "I didn't enjoy it" and "Enjoyed the dynamics of AL".

Fourteen questions were used to test how students viewed the AL set. The 2004 cohort gave 39 "disagree to very strongly disagree" responses compared to only one in the 2005 cohort. There were significant differences in the students' perception of the overall benefits of the AL sets, with a mean score for this section of the questionnaire varying between 2.6 in the 2004 cohort and 1.7 in the 2005 cohort. In particular, the following items were significantly improved in the second cohort: a good forum for sharing ideas, a reflective group, a dynamic learning environment, providing 
constructive feedback, focussing on learning and action, providing time and space for silences and a non-judgmental environment. Even where the differences between the two cohorts did not reach significant levels, the results demonstrated tendencies towards improvement, e.g. Q10 "helpful supportive group" - mean score for Cohort $2004=1.93$ vs. 1.42 for Cohort 2005 (see Table 1 for a summary of the analysis of the section of the questionnaire that relates to the students' perception of their own AL sets). The few comments made by the students identified different perspectives: the use of the set "very supportive non judgmental environment" or personal reflection on their progress in using the skills required to make the AL set more productive "I did not master art of asking questions properly - need to work on this aspect".

\section{Table 1 HERE}

Six questions were used to explore students' perception of the value of the AL set advisors. There were significant improvements in the students' perception of the role of the set advisor in the second cohort. No "disagree" answer was selected for the second cohort whereas five of the six questions had attracted a total of 20 negative responses in the 2004 cohort. The overall mean scores for this section varied between 2.6 in 2004 and 1.6 in 2005. The students were significantly more likely to perceive that the set advisors understood their role as a facilitator rather than as a chair, leader or lecturer (3.13 vs. $1.75, U=42.5, p=0.017)$, had the appropriate skills and qualities to enable the $\mathrm{AL}$ set to benefit from $\mathrm{AL}(2.8$ vs. $1.6, U=49.5, p=$ 
0.034), encouraged the AL set to understand and learn (2.6 vs. 1.6, $U=$ $45.5, p=0.038)$, and helped and encouraged students ( 2.5 vs. $1.3, U=50.0$, $p=0.034)$. There was no difference in the perception of the ability of the set advisors to encourage the AL set to listen, question and think or to help students focus on their tasks or projects, although the trends were positive. Comments made by students at this stage of the questionnaire were generally very positive "set advisor was excellent", "excellent resource, role model and facilitator". They also identified that both the AL set and the set advisor were experiencing changes of role: "occasionally the set advisor gave answers rather than questioning", but also recognising the challenges that students faced in this new situation "privileged to have a very supportive AL set advisor, however we may not always have just used her as a set advisor and asked her comments and feedback".

Nine questions were used to explore how participants viewed their own performance as AL set members. Thirty negative responses were recorded for the 2004 cohort compared to only two for the 2005 cohort. All the questions attracted some "disagree" scores in the first group compared to only one question in the second group (AL set members prepared to maximise their airspace). The overall score for this section of the questionnaire also demonstrated an improvement, varying between 2.8 in the 2004 cohort and 1.9 in the 2005 cohort. Seven questions dealing with communication skills demonstrated significant improvement: listening skills (2.5 vs. $1.5, U=33.0, p=0.003)$, not interrupting ( 2.5 vs. $1.6, U=30.5, p=$ 
0.002 ), empathy ( 2.4 vs. $1.8, U=52.5, p=0.038$ ), challenging ( 2.9 vs. 1.8 , $U=31.5, p=0.003$ ), helpful questions ( 2.9 vs. $1.9, U=36.5, p=0.005$ ), clear questions (3.0 vs. $2.0, U=39.0, p$ 0.009) and giving information (2.9 vs. 1.9, $U=31.5, p=0.002)$. Two questions dealing with the students' personal responsibility for preparing for their participation in the AL set meetings did not reveal significant differences: students were not significantly more likely to report that they had prepared beforehand to maximise their airspace time, nor to have found the suggested action plan useful, even though the positive trends were demonstrated. In this section, they all dealt with their perception of their own role and two main aspects were identified in the few comments made by the respondents: their personal responsibility for their own learning "did not always prepare my problem [and so] did not always achieve goals", and the development of skills "very important for me to learn not to interrupt" or "questioning was a skill I developed as time went on. I learnt the importance of listening and being listened to and the empowerment of being challenged in a safe environment".

Four further questions explored students' perception of their AL experience in terms of future application to their professional roles. The 2004 cohort registered 17 negative answers, compared to none in the 2005 cohort. The differences between the two cohorts were significant for each of the four statements, demonstrating that the 2005 students were significantly more likely to perceive that the AL skills and principles would have useful 
application in their supervisor of midwives and other professional roles: skills learning through AL will be useful when appointed as supervisor of midwives ( 2.9 vs. $1.8, U=34.0, p=0.008$ ), would consider using AL principles as supervisor of midwives (3.2 vs. $1.8, U=35.5, p=0.010$ ), skills learned through AL useful in other professional roles (2.8 vs. 1.7, $U=34.5$, $p=0.008)$ and would consider using AL principles in other professional roles (3.0 vs. $1.9, U=42.5, p=0.027)$.

\section{Discussion}

This evaluation aimed to assess the usefulness and acceptability of AL to students undertaking a preparation programme for supervisors of midwives, and potential improvements in the delivery and experience of AL between two consecutive cohorts of supervisor of midwives students in 2004 and 2005. The learning intentions and outcomes for the supervisor of midwives preparation programme aim to enable students to develop the knowledge and attitudes needed to fulfil their roles and responsibilities. As many aspects of the supervisor of midwives' role involve a problem solving approach (Stapleton et al., 1998), the AL principles should have some application to the preparation of the supervisor of midwives' role (Learmonth \& Pedler, 2004; Learmonth, 2005). However, learning through AL is mediated through group interaction often based on communal projects (Booth et al., 2003), whereas the usual further educational route for supervisors of midwives has generally been either the distance learning route, taught courses with or without mentoring by another supervisor of 
midwives (ENB, 1995; ENB, 2001; NMC, 2002). The experience of AL is still limited in programmes of initial or continuing education for midwives; indeed only one supervisor of midwives student had previous experience of $\mathrm{AL}$ and this was in the context of her professional development within her own organisation. The experience of AL was also a new educational approach for the three AL set advisors who had undertaken specific training for the purpose of facilitating the AL component within this programme.

The differences found between the 2004 and the 2005 cohorts of students may suggest possible differences in the characteristics of the students recruited for the two courses. However, the criteria and the procedures used for the nomination and selection of supervisor of midwives students remained the same throughout this period. The students came from the same pool of maternity units across London and surrounding counties. If essential differences between students cannot be demonstrated, the findings might suggest that the AL set advisors were developing and improving their skills, thereby increasing students' satisfaction with the AL set experience.

One set advisor was an experienced lecturer and supervisor of midwives; the second was an experienced lecturer but less experienced supervisor of midwives and the third was the most experienced lecturer but was not a supervisor of midwives. From the beginning of the introduction of AL in the supervisors of midwives' programme of preparation, the three set advisors who were already experienced midwifery lecturers for pre- and 
post-registration midwifery students undertook training and preparation for this role. This consisted of an intensive preparation day from an experienced AL facilitator, associated with extensive reading to ensure sound understanding of the theory and practice of AL generally and the role of the set advisor in particular. Some of their existing educational skills were transferable, but to ensure and improve the quality of AL, the set advisors met regularly to debrief and reflect on their experiences and professional development as set advisors and to ensure the adherence to the AL principles.

Following students' evaluation which identified the need for greater preparation of the students for the AL experience, the 2005 students were given more information about the theory, philosophy, principles and application of $\mathrm{AL}$ in the context of the programme of preparation for supervisors of midwives. The AL set advisors decided to refer regularly and purposefully to the AL principles throughout the six AL days for this cohort, and this was associated with slight but not significant improvement in the perception of the preparation between the two cohorts, but it is useful to note that the level of satisfaction was already relatively high in 2004 (see Table 1). Students' perception of the role of the set advisor demonstrates statistical improvement (see Table 4); this may be associated with further experience and greater expertise over the three years of the programme delivery. 
AL was a new experience for all but one student. At the end of their course, the 2005 cohort stated that they would consider using AL in their future supervisor of midwives' role and in the context of their other professional responsibilities. The differences between the two cohorts were highly significant. This finding mirrors the results of other studies which have examined the perceptions of practitioners who have undertaken programmes of preparation for other specialist roles (Graham, 2005; Graham \& Wallace, 2005). It also supports the assertion that AL could not be managed effectively without sound preparation and commitment (Booth et al., 2003; Learmonth, 2005).

\section{Conclusion}

On the basis of a literature search, the principles of AL, though mostly reported in the context of industry and management, had been identified as a potentially useful approach in the panoply of the learning and teaching strategies that could be deployed in the preparation programme for supervisors of midwives. AL had not been formally adopted and formally evaluated by other colleagues in the School of Nursing and Midwifery at the University of Hertfordshire. The three experienced midwifery lecturers involved in the programme development, its validation and subsequent implementation were also the set advisors for both cohorts. Although they had followed a preparation programme to help them develop this new role, they had not able to observe an AL set before taking on the role of set advisor. Their lack of AL experience was balanced by their enthusiasm and 
commitment. This was further demonstrated by the desire to add a research element to the existing quality monitoring process to ensure a sound evaluation of the quality and acceptability of AL with students and, where appropriate, disseminate their findings.

This study demonstrated that AL was acceptable to supervisor of midwives students and was perceived as potentially useful for supervision and other professional roles. Improvements were identified between two consecutive cohorts; this may be associated with increasing AL set advisors' experience and expertise. On-going evaluation will be necessary to ensure that these findings are reliable over time. This evaluation was undertaken on completion of the course and further research would be useful to determine if the potential effects of AL could be sustained at medium and long term and therefore demonstrate a systematic improvement in the quality of statutory supervision of midwives, and potentially other professional roles. Similarly further research would be useful to examine the development of the skills of AL set advisors and its effects on the delivery of the course. The evaluation to date has not included the exploration of the experiences of the three present set advisors. However, the team of midwifery lecturers involved in the delivery of the preparation programme for supervisors of midwives is growing and some negotiation regarding the possibility of exploring the perception of the more experienced lecturers and those who join the group has already taken place. This should enable some evaluation of the level to which experience may contribute to changes in the perception 
of the quality and usefulness of the approach with students and identify areas that might enable new set advisors to become more competent and confident when taking on this role. Other research methods, potentially including participant or non-participant observations, or in-depth interviews, will provide a basis for further exploration of the short, medium and long term experience of students and lecturers who are taking part in this new approach in programmes of preparation for supervisors of midwives. 
Table 1 - Students' perception of their AL set - Cohorts 2004 and 2005

\begin{tabular}{|c|c|c|c|c|c|}
\hline Questions & $\begin{array}{r}\text { Mean } \\
04 \\
\mathrm{n}=15\end{array}$ & $\begin{array}{r}\text { Mean } \\
05 \\
\mathrm{n}=12\end{array}$ & $\begin{array}{l}\text { Dis- } \\
\text { agree } \\
04-\mathrm{n}\end{array}$ & $\begin{array}{l}\text { Dis- } \\
\text { agree } \\
05-\mathrm{n}\end{array}$ & $\begin{array}{r}p \text { value } \\
\text { Mann } \\
\text { Witney }\end{array}$ \\
\hline Q6. members helped my learning & 2.20 & 1.67 & & & 0.071 \\
\hline Q7. set useful ground rules & 2.20 & 1.67 & 1 & & 0.162 \\
\hline Q8. forum for sharing ideas* & 2.47 & 1.50 & 4 & & 0.048 \\
\hline Q9. resource group & 2.53 & 1.83 & 2 & & 0.122 \\
\hline Q10. helpful supportive group & 1.93 & 1.42 & 1 & & 0.170 \\
\hline Q11. reflective group* & 2.47 & 1.42 & 2 & & 0.014 \\
\hline $\begin{array}{l}\text { Q12. dynamic learning } \\
\text { environment * }\end{array}$ & 3.00 & 1.83 & 5 & 1 & 0.044 \\
\hline Q13. adequate "airspace" & 2.47 & 1.92 & 2 & & 0.226 \\
\hline $\begin{array}{l}\text { Q14. asked helpful \& challenging } \\
\text { questions }\end{array}$ & 3.00 & 2.08 & 5 & & 0.088 \\
\hline Q15. listened actively & 2.33 & 1.67 & 1 & & 0.080 \\
\hline Q16. gave constructive feedback* & 2.79 & 1.83 & 3 & & 0.042 \\
\hline $\begin{array}{l}\text { Q17. focussed on learning \& } \\
\text { action* }\end{array}$ & 3.07 & 1.75 & 5 & & 0.010 \\
\hline $\begin{array}{l}\text { Q18. provided time \& space for } \\
\text { silences* }\end{array}$ & 3.27 & 1.58 & 5 & & 0.002 \\
\hline Q19. not judgmental* & 2.40 & 1.33 & 3 & & 0.018 \\
\hline Total & & & 39 & 1 & \\
\hline
\end{tabular}

* denotes significant improvement in the 2005 cohort 


\section{Notes on Contributors}

Marianne Mead is a Principal Lecturer, Midwifery, and Associate Research Leader. Her areas of interest centre on perception of risk and decision making, as well as the application of the European Directives and the development of research for midwives in Europe.

Carole Yearley is a Senior Lecturer, Midwifery, and a Supervisor of Midwives at the University of Hertfordshire. She is currently the programme tutor for the PgCert Supervision of Midwives. Her previous MSc in Medical Anthropology examined students' perception of "fitting in" the clinical environment.

Christine Lawrence is a Principal Lecturer, Midwifery. Her area of interest includes coaching for professional development, and she is one of the three Action Learning set advisors on the programme.

Cathy Rogers is a Consultant Midwife, Supervisor of Midwives and a Senior Lecturer, Midwifery. She was part of the team that led the initial development of the programme at Masters' level; she continues to be involved in the teaching and assessment of the current programme. 


\section{References}

Alexander, J., Anderson, T. and Cunningham, S. (2002) An evaluation by focus group and survey of a course for Midwifery Ventouse Practitioners Midwifery 18(2), 165-72.

Bloomfield, L., Rogers, C., Townsend, J., Wolke, D. and Quist-Therson, E. (2003) The quality of routine examinations of the newborn performed by midwives and SHOs; an evaluation using video recordings Journal of Medical Screening 10(4), 176-180.

Booth, A., Sutton, A. and Falzon, L. (2003) Working together: supporting projects through action learning Health Information and Libraries Journal 20(4), 225-231.

Donnison, J. (1988) Midwives and medical men . (High Barnet, Herts.: Historical Publications).

Duerden, J. (2005) Supporting decision making through supervision, in: Raynor, M., Marshall, J. and Sullivan, A. (·Ed.^Eds.) Decision making in midwifery practice.(London: Elsevier), 157-168.

ENB (1995) Midwifery educational resource pack : the challenge of 'Changing childbirth'. (London: ENB).

ENB (2001) Preparation for Supervisors of Midwives. (London: ENB).

Fennell, L. (1995) Midwives and ultrasound Modern Midwife 5(1), 36-7.

Graham, I. (2005) Action learning as a tool for developing networks and building evidence-based practice in public health Action Learning: Research and Practice 2(1), 97-104.

Graham, I. W. (1995) Reflective practice: using the action learning group mechanism Nurse Education Today 15(1), 28.

Graham, I. W. and Wallace, S. (2005) Supporting the role of the nurse consultant - an exercise in leadership development via an interactive learning opportunity Nurse Education Today 25(2), 87-94.

Heagerty, B. (1996) Reassessing the guilty: the Midwives Act and the control of English midwives in the early 20th century, in: Kirkham, M. ( $\cdot$ Ed. ${ }^{\wedge}$ Eds.) Supervision of midwives.(Hale, Cheshire: Books for Midwives), 13-27.

Knowles, M. S. (1984) Andragogy in action. (San Francisco: Jossey-Bass).

Learmonth, A. (2005) Action learning as a tool for developing networks and building evidence-based practice in public health Action Learning: Research and Practice 2(1), 97-104.

Learmonth, A. and Pedler, M. (2004) Auto Action Learning: a tool for policy change: Building capacity across the developing regional system to improve health in the North East of England Health Policy 68(2), 169-181.

Magill-Cuerden, J. (1994) Ultrasound--routine practice or practised routine? Modern Midwife 4(3), 4-5.

Marquardt, M. and Waddill, D. (2004) The power of learning in action learning: a conceptual analysis of how the five schools of adult learning theories are incorporated within the practice of action learning Action Learning: Research and Practice 1(2), 185-202. 
McGill, I. and Beaty, L. (1995) Action learning : a guide for professional, management and educational development. (London: Kogan Page).

NMC (2002) Professional standards for education and practice. (London: Nursing and Midwifery Council).

NMC (2004) Midwives rules and standards. (London: NMC).

Parslow, L. (1997) A midwife ventouse practitioner Midwives 110(1314), $175-7$.

Pedler, M. (2005) Editorial - Critical action learning Action Learning: Research and Practice 2(1), 1-6.

Revans, R. (1998) ABC of Action Learning: Empowering managers to act and to learn from action. (London: Lemos \& Crane).

Rogers, C., Bloomfield, L. and Townsend, J. (2003) A qualitative study exploring midwives' perceptions and views of extending their role to the examination of the newborn baby Midwifery 19(1), 55-62.

Rogers, C. and Hallworth, C. (2000) Supervision at Masters Level, in: Kirkham, M. $\left(\cdot\right.$ Ed. ${ }^{\wedge}$ Eds.) Developments in the supervision of midwives.(London: Books for Midwives.

Rosser, M., Rice, A. M., Campbell, H. and Jack, C. (2004) Evaluation of a mentorship programme for specialist practitioners Nurse Education Today 24(8), 596-604.

Stapleton, H., Duerden, J. and Kirkham, M. (1998). Evaluation of the impact of the supervision of midwives on professional practice and the quality of midwifery care. Research Highlights. ENB. London, ENB. 29: 4.

Weinstein, K. (1999) Action learning: a practical guide. (Brookfield, VT: Gower).

Wolke, D., Dave, S., Hayes, J., Townsend, J. and Tomlin, M. (2002) A randomised controlled trial of maternal satisfaction with the routine examination of the newborn baby at three months post birth Midwifery 18(2), 145-54. 